\title{
Spontaneous Regression of a Metastasis from Melanoma: A Case Report
}

\author{
Waldec Jorge David Filho ${ }^{1 *}$, Larissa Martins Machado ${ }^{1}$, Ana Luísa de Castro Baccarin ${ }^{2}$ and \\ Paula Lemos Crisóstomo ${ }^{2}$ \\ ${ }^{1}$ Hospital Alemão Oswaldo Cruz, Clinical Oncology - São Paulo, Brazil \\ ${ }^{2}$ Instituto Brasileiro de Controle de Câncer, Clinical Oncology- São Paulo, Brazil \\ *Corresponding author: Waldec Jorge David Filho, Hospital Alemão Oswaldo Cruz, Clinical Oncology - São Paulo, Brazil
}

$\begin{array}{ll}\text { ARTICLE INFO } & \text { ABSTRACT } \\ \end{array}$

Received: May 15, 2020

Published: 幽 June 03, 2020

Citation: Waldec Jorge DF, Larissa Martins M, Ana Luísa de CB, Paula Lemos C. Spontaneous Regression of a Metastasis from Melanoma: A Case Report. Biomed J Sci \& Tech Res 28(1)-2020. BJSTR. MS.ID.004593.
Keywords: Melanoma Spontaneous Regression

Abbreviations: SR: Spontaneous Regression; CT: Computerized Tomography; PET: Positrons Emission Tomography; BCG: Bacillus Calmette Guérin

\section{Introduction}

Spontaneous regression (SR) of cancer was initially defined by Stewart, [1] and revised by Cole [2]. According to them "it is the partial or complete disappearance of a malignant tumor in the absence of all treatment or in the presence of therapy which is considered inadequate to exert a significant influence on neoplastic disease". The authors also point out that SR does not mean a complete disappearance of the tumor, nor is it synonymous with cure $[1,2]$. Furthermore, they emphasize SR is not an adequate term, "because there is obviously a cause of the regression", although it is unknown. The likelihood of SR in melanoma is one of the biggest among all subtypes of cancer. In a collection of 176 cases reported by Cole during the1960's, there were predominately hypernephroma, neuroblastoma and melanoma, with 31, 29 and 19 cases, respectively [2]. Primary lesions regress more frequently than the secondary ones. Some degree of histological regression can be identified in up to $50 \%$ of cases $[3,4]$, but a complete disappearance of the tumor happens in a lesser proportion. Some patients present with a metastatic melanoma, but the methods routinely used for staging may be unable to identify the primary site. Several reports from medical literature estimates 4\%-6\% of those cases [5,6], however, that kind of phenomenon is rarer when the disease present with metastases.
It has been said the first case of SR was described in 1889 [7] and it remains a rare observation. As far as we know, less than one hundred cases of complete regression of metastatic melanoma have been described so far. Conversely, the probability of SR of metastasis from melanoma is less than $1 \%[8,9]$. The exact mechanism of SR in melanoma is not yet fully understood, but immunological factors must be considered. Melanoma cells are known to be immunogenic and to contain tumor-specific antigens which may cause production of circulating humoral antibodies, as well as other immunological reactions.

\section{Case Report}

We describe a case of a 69-year-old male patient, diagnosed with malignant melanoma when he was 64 . His co morbidities were systemic hypertension and dyslipidemia, and there was no family history of cancer. The primary lesion was located in his left arm and it was respected in February 2015. The histological analysis showed the lesion was completely removed with the following characteristics: Below $2.1 \mathrm{~mm}$, vertical growth phase, Clark IV, mitotic index 9/10, no vascular invasion, ulceration present and margins free of malignancy - pT3b; immunopheno type BRAF wild-type. The initial procedure required a wider excision; this was performed two months later and there was no residual 
melanoma. At the same time the patient underwent a left axillary lymphadenectomy in which there was malignant involvement of one lymph node, of the sixteen removed. In December 2015 a chest computerized tomography (CT) scan showed a small nodule $(18 \mathrm{~mm})$ in his pulmonary ligulae (Figure 1). A positrons emission tomography (PET) scan confirmed this finding with a mild hyper metabolic activity (SUV 2.8); no other lesions were seen.

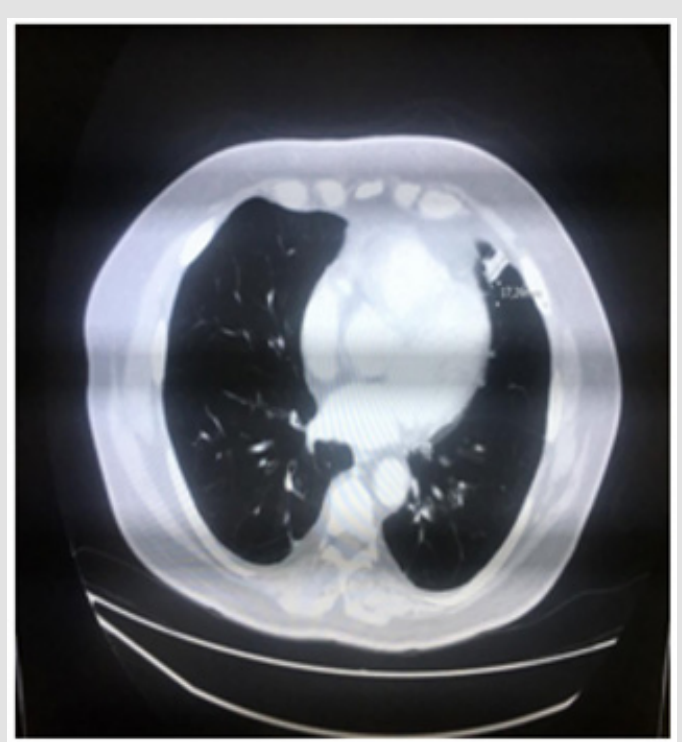

Figure 1: Chest CT showing pulmonary nodule on the left.

In March 2016 a transthoracic biopsy of this pulmonary nodule was performed and the microscope confirmed a metastatic melanoma. Although, in April 2016 (ten months since diagnosis) a new CT scan showed the nodule was smaller $-10 \mathrm{~mm}$ in the greatest diameter. Based on this unusual finding the patient was closely monitored and was clinically reviewed every 3 months by the surgical and oncological teams. The nodule continued regressing for the next months and in November 2016 a new chest CT showed no longer the lesion. In its place remained just a tissue resembling fibrosis. A new chest CT scan performed in October 2017 (22 months since the nodule was first seen) was totally normal (Figure 2). The patient persisted in follow-up and his last evaluation was in January 2020; he was healthy and without neoplastic symptoms.

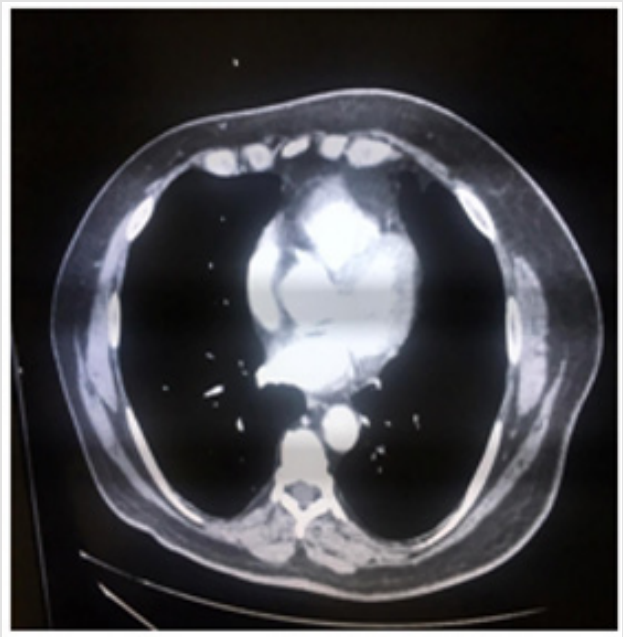

Figure 2: Chest CT showing the pulmonary nodule has regressed.

\section{Discussion}

In this case the metastatic melanoma with SR occurred in a male patient; it is known there is a lesser prevalence of this kind of cancer in females. Lungs are the main visceral sites from which metastases can regress. Both findings are in accordance to medical literature. The characteristics of the patients whose metastases from melanoma reach SR can be mainly withdrawn from an article review published by Kalialis, et al. in 2009 in which they reported 75 cases, since 1866 [10]. Below, these characteristics are described in a summarized form (Table 1). The patient's age were divided into two groups: more or less 65 years, just to show the proportion of elderly ones. The number between parentheses, whenever present, indicates the real age of the patients. The average age in women is 43.3 years, and in men 56.9. SR occurs more commonly in males than in females; particularly in lesions of trunk in comparison to lesions of other human body areas [7]. Kalialis, et al. still accentuate the most common sites from which metastases can spontaneously regress are cutaneous or subcutaneous tissues, followed by lymph nodes. Other less common sites are, in order of probability, lungs, liver, brain and bowels [7,10]. Remarkably, the main factor associated with SR in virtually all the patients was some kind of operative trauma, followed by infection and radiotherapy.

Table 1: Characteristics of the patients whose metastases from melanoma reach SR.

\begin{tabular}{|c|c|c|c|c|c|c|c|c|}
\hline \multicolumn{2}{|c|}{ Autor } & $\begin{array}{c}\text { Kalialis, et. al } \\
{[10]}\end{array}$ & $\begin{array}{l}\text { Bramhall, et. } \\
\text { al[13] }\end{array}$ & $\begin{array}{l}\text { D'Andrea, } \\
\text { Reddy [11] }\end{array}$ & $\begin{array}{l}\text { Behnia, } \\
\text { et. al[12] }\end{array}$ & $\begin{array}{c}\text { David Filho, } \\
\text { et. al }\end{array}$ & Total & $\%$ \\
\hline \multicolumn{2}{|c|}{ Number of cases } & 75 & 6 & 1 & 1 & 1 & 84 & 100 \\
\hline \multirow{3}{*}{ Age (years) } & $<65$ & 64 & - & $1(42)^{*}$ & $1(55)^{*}$ & 0 & 66 & 78,5 \\
\hline & $>65$ & 09 & - & 0 & 0 & $1(69)^{*}$ & 10 & 11,9 \\
\hline & Indeterminate & 02 & 6 & 0 & 0 & 0 & 08 & 9,5 \\
\hline \multirow{3}{*}{ Gender } & Female & 34 & - & 1 & 1 & 0 & 36 & 42,8 \\
\hline & Male & 41 & - & 0 & 0 & 1 & 42 & 50 \\
\hline & Indeterminate & 0 & 6 & 0 & 0 & 0 & 06 & 7,1 \\
\hline
\end{tabular}




\begin{tabular}{|c|c|c|c|c|c|c|c|c|}
\hline \multirow{2}{*}{ Regressiontype } & Complet & 55 & 3 & 0 & 0 & 1 & 59 & 70,2 \\
\hline & Partial & 20 & 3 & 1 & 1 & 0 & 25 & 29,8 \\
\hline \multirow{7}{*}{ Associated factortoSR } & Operations & 75 & 6 & 0 & 1 & 1 & 83 & 98,8 \\
\hline & Infection & 21 & 0 & 0 & 0 & 0 & 21 & 25 \\
\hline & Radiation & 11 & 0 & 1 & 0 & 0 & 12 & 14,3 \\
\hline & Pregnancy & 05 & 0 & 0 & 0 & 0 & 05 & 5,9 \\
\hline & Antibodies I-131 & 03 & 0 & 0 & 0 & 0 & 03 & 3,6 \\
\hline & Chemotherapy & 02 & 0 & 0 & 0 & 0 & 02 & 2,4 \\
\hline & Vaccination & 01 & 0 & 0 & 0 & 0 & 01 & 1,2 \\
\hline \multirow{2}{*}{ Cutaneousdissemination } & Yes & 47 & 4 & 1 & 0 & 0 & 52 & 61,9 \\
\hline & No & 28 & 2 & 0 & 0 & 1 & 31 & 36,9 \\
\hline \multirow{8}{*}{ Metastatic site } & Lymph node & 39 & 2 & 0 & 0 & 0 & 41 & 48,8 \\
\hline & Lung & 10 & 1 & 0 & 1 & 1 & 13 & 15,5 \\
\hline & Cerebral & 08 & 0 & 1 & 0 & 0 & 09 & 10,7 \\
\hline & Bowell & 04 & 0 & 0 & 0 & 0 & 04 & 4,8 \\
\hline & Liver & 08 & 0 & 0 & 0 & 0 & 08 & 9,5 \\
\hline & Bone & 04 & 0 & 0 & 0 & 0 & 04 & 4,8 \\
\hline & Splenic & 01 & 0 & 0 & 0 & 0 & 01 & 1,2 \\
\hline & Choroidal & 01 & 0 & 0 & 0 & 0 & 01 & 1,2 \\
\hline
\end{tabular}

Why can a lesion spontaneously regress? As it has been mentioned, the most important factors that can contribute to such an occurrence are surgical trauma and infection, in addition to immunological factors. Interestingly, SR of metastases can occur following irradiation of other metastasis at distant locations - it is known as episcopal effect; systemic antitumor response induced by cerebral irradiation can also be noticed [11]. The patient we have described underwent a biopsy to clarify the nature of the pulmonary lesion. We believe such procedure ended up releasing some antigens to his immune system. Consequently, there could have been a mobilization of effect or cells to the tumor. Or maybe it was just a coincidence, because the regression was about to occur when the biopsy was performed. In both situations, there should have been a major effectiveness of the immune system. Unequivocally, the lesion regressed completely, anyway. A similar SR of a metastatic melanoma pulmonary following biopsy has been reported as well [12]. The importance of a surgical procedure in promoting regression in metastatic melanoma can also be illustrated by Bram hall, et al. in a paper published in 2014 [13]. They did a retrospective review over a 15 year period and reported 6 cases of SR of metastatic melanoma. According to their own words, those cases are "clinical evidence of the abs copal effect" surgically induced, we would add.

Many other less relevant factors can be implied. Among them, we can cite BCG (Bacillus Calmette Guérin) and rabies vaccinations, blood transfusions, endocrine factors such as pregnancy or terminations, several alternative therapies, in addition to conditions such as xeroderma pigmentosum, diabetes mellitus, nephrolithias is, prostatic hyperplasia and peptic ulcer [10]. In all the above situations there seems to be a chronic stimulation of the immune system. Anyways, such occurrences are rare. Some factors appear to be involved with the start of cancer regression and others with its maintenance or continuation. The operative trauma is probably related to the beginning of regression. It is hard to make such a statement unequivocally; perhaps it is just a "circumstantial evidence" [13]. The infection rate in patients demonstrating regression of metastatic melanoma can be as high as 28\% [14]. There can be a correlation between infection and cancer regression. Infection, as well as other ways of immune system stimulation, can play some role in increasing the natural defenses against neoplasia. In the past, some breast cancer patients had erysipelas-induced in order to provoke some tumor regression.

Nevertheless, it seems melanoma survival rates are worse in immune suppressed patients than in normal ones [15]. There may also be a regional reduction in immune activity within lymph nodes prior to the development of lymph node metastases [16]. Supposedly, there is a balance between host defenses and proliferation of cells evading the immunological surveillance - the so called malignant cells. The correct mechanisms favoring one or another direction are not totally understood. Within the same tumor progressing regionscan coexist with foci of regression; this is a reflection of the struggle before the final outcome [17-19]. A rigorous description of the complex mechanisms which comprehend the immune system, as a whole, is beyond this paper. In summary, the role played by the cytotoxic $\mathrm{T}$ lymphocyte is critical for the attempt of suppressing the tumor growth. In general, the efficacy of such cells is down-regulated when the tumor proliferates. The modern immunotherapy tries to up-regulate their effectiveness as well as releasing them to attack 
the neoplasia. Today, several drugs are available to accomplish this mission through different paths. The main class of those drugs is the immune-check point inhibitors; they are capable of favoring the host to recognize tumor tissue as non-self $[20,21]$.

A somewhat different view of melanoma SR has been recently proposed by Motofei [22]. According to him, that is an excellent model of a "possible autoimmune rejection". In order to support his theory, there is the observation that melanoma SR occurs more frequently in men than women, with a ratio of 2.7:1 [23]. A possible explanation for this observation is that men are not projected "as a host for gestational immune-tolerance". Motofei adds that cancer should no longer be considered a cellular problem as it has been so far; "it is a supra-cellular problem represented by inadequate evolution of complex process such as embryogenesis, development regeneration, etc. [22].

\section{Conclusion}

SR of metastatic disease in melanoma remains poorly understood. There have been some known factors involved in such a process, but we have not been able to select patients for this kind of occurrence. Aught, it seems to be a favorable prognostic factor, even though subsequent relapse may happen. Ultimately, tumor growth regressions are the outcome of a fight between host defenses and promotional factors produced by the tumor itself or in response to its presence. Nowadays, the melanoma treatment goals are to stimulate the immune system, in order to eliminate the malignant cells. Actually, the achievements of immunotherapy in the treatment of melanoma are among the most remarkable developments in cancer therapy over the last decades.

\section{Acknowledgements}

The authors thank the patient who permitted to be reported.

\section{Conflict of Interest}

The authors declare no conflict of interest.

\section{References}

1. Stewart FW (1952) Experiences in spontaneous regression of neoplastic disease in man. Tex Rep Biol Med 10: 239-253.

2. Cole WH (1981) Efforts to explain spontaneous regression of cancer. J Surg Oncol 17: 201-209.

3. Bodurtha AJ (1979) Spontaneous regression of melanoma In: Clark WH, Goldman LI, Mastrangelo LM, editors. Human melanoma. New York, USA: Grune and Stratton pp. 227-241.

4. Nathanson L (1976) Spontaneous regression of melanoma: a review of the literature on incidence, clinical features and possible mechanisms. Natl Cancer Inst Monogr 44: 67-76.
5. Baab GH, McBride CM (1975) Malignant melanoma: The patient with an unknown site of primary origin. Arch Surg 110: 896-900.

6. Giuliano AE, Moseley HS, Morton DL (1980) Clinical aspects of unknown primary melanoma. Ann Surg 191: 98-104.

7. Hurwitz PJ (1991) Spontaneous regression of metastatic melanoma. Ann Plast Surg 26: 403-406.

8. Milton GW, Brown MML, Gilder M (1967) Melanoma with an occult primary lesion. Br J Surg 54: 651-658.

9. Maurer S, Kölmel KF (1998) Spontaneous regression of advanced melanoma. Onkologie 21: 14-18.

10. Kalialis LV, Drzewiecki KT, Klyver H (2009) Spontaneous regression of metastases from melanoma: Review of the literature. Melanoma Res 19: 275-282.

11. D’Andrea MA, Reddy GK (2019) Extracranial systemic antitumor response through the abscopal effect induced by brain radiation in a patient with metastatic melanoma. Radiat Oncol Journal 37(4): 302-308.

12. Behnia F, Zare M, Elojeimy S (2018) Spontaneous regression of a metastatic melanoma pulmonary deposit following biopsy. Radiol Case Rep 13(3): 580-582.

13. Bramhall RJ, Mahady K, Peach AHS (2014) Spontaneous regression of metastatic melanoma: Clinical evidence of the abscopal effect. EJSO 40: $34-41$

14. Ribeiro S, Moscarella E, Ferrara G, Piana S, Argenziano G, Longo C (2016) Regression in cutaneous melanoma: A comprehensive review from diagnosis to prognosis. J Eur Acad Dermatol Venereol 30(12): 20302037.

15. Brewer JD, Christenson LJ, Weaver AL, et al. (2011) Malignant melanoma in solid transplant recipients: collection of database cases and comparison with surveillance, epidemiology, and end results data for outcome analysis. Arch Dermatol 147: 790-796.

16. Smith JL, Stehlin JS (1965) Spontaneous regression of primary melanomas with regional metastases. Cancer 18: 1399-1415.

17. Bennett WH (1889) Some peculiarities in the behavior of certain malignant and innocent growths. Lancet 1: 3-7.

18. Kelly JW, Sagebiel RW, Blois MS (1985) Regression in malignant melanoma. A histologic feature without independent prognostic significance. Cancer 56: 2287-2289.

19. Challis GB, Stam HJ (1990) The spontaneous regression of cancer. A review of cases from 1900 to 1987. Acta Oncol 29: 545-550.

20. Mahoney MK, Freeman GJ, McDermott DF (2015) The next immunecheckpoint inhibitors: PD-1/PD-L1 blockade in melanoma. Clin Therap 37(4): 764-782.

21. Villadolid J, Amin A (2015) Immune checkpoint inhibitors in clinical practice: update on management of immune-related toxicities. Transl Lung Cancer Res 4(5): 560-575.

22. Motofei IG (2019) Melanoma and autoimmunity: Spontaneous regressions as a possible model for new therapeutic approaches. Melanoma Res 29: 231-236.

23. Allen EP (1955) Melanoma, spontaneous regression after pregnancy. $\mathrm{Br}$ Med J 2: 1067 
ISSN: 2574-1241

DOI: 10.26717/BJSTR.2020.28.004593

Waldec Jorge David Filho. Biomed J Sci \& Tech Res

(C) $(9)$ This work is licensed under Creative

Submission Link: https://biomedres.us/submit-manuscript.php

$\begin{array}{ll}\text { BIOMEDICAL } & \text { Assets of Publishing with us } \\ \text { RESEARCHES } & \text { - Global archiving of articles } \\ \text { - Immediate, unrestricted online access }\end{array}$

